\title{
QoS in FANET Business and Swarm Data
}

\section{Jesús Hamilton Ortiz ${ }^{1}$, Carlos Andrés Tavera Romero ${ }^{2, *}$, Bazil Taha Ahmed ${ }^{3}$ and Osamah Ibrahim Khalaf}

\author{
${ }^{1}$ Close Mobile R\&D Telecommunications LS, Madrid, España \\ ${ }^{2}$ COMBA I+D Research Group of Universidad Santiago de Cali, Cali, Colombia \\ ${ }^{3}$ Autonomous of Madrid University, Madrid, España \\ ${ }^{4}$ Al-Nahrain Nanorenewable Energy Research Center in Al-Nahrain University, Bagdad, Iraq \\ *Corresponding Author: Carlos Andrés Tavera Romero. Email: carlos.tavera00@usc.edu.co \\ Received: 22 September 2021; Accepted: 04 January 2022
}

\begin{abstract}
This article shows the quality of services in a wireless swarm of drones that form an ad hoc network between them Fly Ad Hoc Networks (FANET). Each drone has the ability to send and receive information (like a router); and can behave as a hierarchical node whit the intregration of three protocols: Multiprotocol Label Switch (MPLS), Fast Hierarchical AD Hoc Mobile (FHAM) and Internet Protocol version 6 (IPv6), in conclusion MPLS + FHAM + IPv6. The metrics analyzed in the FANET are: delay, jitter, throughput, lost and sent packets/received. Testing process was carried out with swarms composed of 10, 20, 30 and 40 units; In this work, the stage with 40 drones was analyzed showing registration processes, and sent messages sequences between different drones that were part of the same swarm. A special analysis about the traffic between drones (end-to-end) was carried out, as well as the possible security flaws in each drone and the current status and future trends in real services. Regarding future trends, in a real environment, we took as a starting point, metrics results obtained in the simulation (positive according to the obtained results). These results gave us a clear vision of how the network will behave in a real environment with the aim to carry out the experiment on a physical level in the near future. This work also shows the experience quality from the service quality metrics obtained through a mathematical model. This quality of experience model will allow us to use it objectively in the agricultural sector, which is a great interest area and is where we are working with drones. Finally in this article we show our advances for a business model applied to the aforementioned agricultural sector, as well as the data analysis and services available to the end customer. These services available to the end customer have been classified into a basic, medium, advanced and plus level.
\end{abstract}

Keywords: Ad hoc home agent (AHA); ad hoc mobile node (AMN); ad hoc correspondent node (ACN); ad hoc mobile anchor point (AMAP);

This work is licensed under a Creative Commons Attribution 4.0 International License, which permits unrestricted use, distribution, and reproduction in any medium, provided the original work is properly cited. 
fast hierarchical AD hoc mobile IPv6 (FHAMIPv6); label switching router (LSR) label edge router (LER); mobile ad hoc networks (MANET) fly ad hoc network (FANET); quality of services (QoS); quality of experience (QoE)

\section{Introduction}

\subsection{FANET Special Features}

Unlike infrastructure networks, in which nodes remain static, Fly Ad Hoc Networks (FANETs) require special considerations in the different layers of the Open System Interconnection (OSI) reference model derived from the mobility of the drones. At higher levels, they must ensure service continuity regardless of the mobility of the nodes, at level 3 (the network layer). Then, it is necessary to have routing protocols to ensure that the established paths are dynamically reconfigured to the extent that the drone, with their mobility, change the topology of the network.

This forces a continuous and dynamic reconfiguration of the routing tables. In the data link layer, it is necessary to recognize the particular technology with which the interface of each node accesses the medium and the particular mechanism (events and metrics), through which it identifies a change in the conditions of performance bond transmission. Therefore, when formulating a solution, it will be necessary to make considerations in each of these levels to ensure a proper integration of the parties and an efficient operation of the solution.

The wireless and mobile computing technologies were developed after the Internet Protocol version 4 (IPv4) development, which was not designed to operate in such complex environment as the Mobile Ad hoc Networks (MANETs). It was necessary then to develop the Mobile Internet Protocol version 4 (MIPv4) [1] protocol to provide adequate services to mobile devices. However, very soon the protocol came up short when mobile nodes performed a handover from one network to another. There were unacceptable delays. Then, extensions diminishing the overload caused by the registration process were developed and delay levels were improved. Including Hierarchical Mobile Internet Protocol (HMIP) [2] and Fast Mobile Internet Protocol (FMIP) [3].

Later, with the advent of Internet Protocol version 6 (IPv6) that took into account the mobile behavior of the nodes, the Fast Handover Mobile Internet Protocol IPv6 (FHMIPv6) was developed incorporating improvements over its predecessors, reducing delay in the transfer and the home network overload. Then considerations to extend the protocol to operate in MANETs networks were made, and FHAMIPv6 appeared. However, this protocol is not properly integrated with all routing protocols and offers deterioration in performance [4].

The authors, in a previous study, conducted an FHAMIPv6 protocol assessment when integrated with Ad-Hoc Routing Agent (AHRA) and compared it with the integration of FHAMIPv6 protocol, when integrated with the Ad Hoc on Demand Distance Vector (AODV) routing protocol. The quality metrics used were delay, jitter, and throughput and packet loss. The experimental evidence showed that FMAMIPv6/AODV provided better integration in throughput. In a later work [5], the integration of the MPLS with Fast Hierarchical Mobile IPv6 (FHMIPv6) was evaluated to ensure that during the 
integration and handover, not only metrics but also the level of quality by default was maintained during the handover. Following, a description of FHAMIPv6 protocol behavior is presented. The initial reference scenario is presented in Fig. 1.

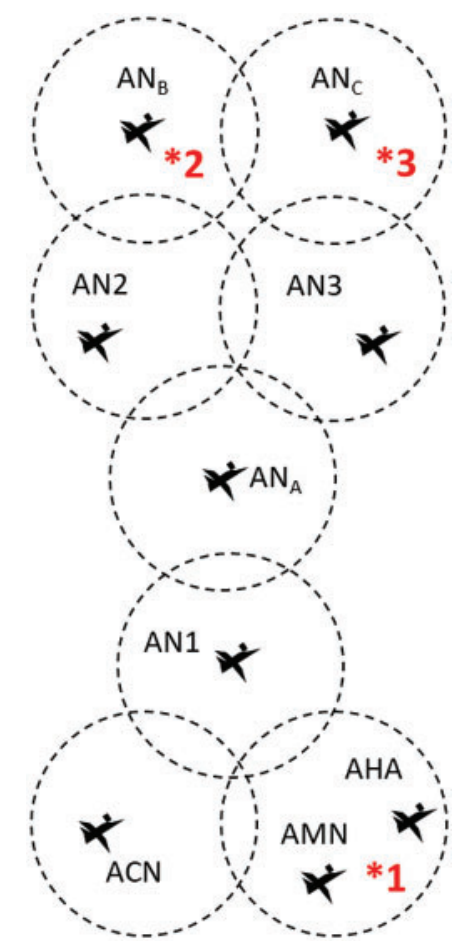

Figure 1: Initial reference scenario

The nodes marked with the numbers 1, 2 and 3 (Red color) are shown. Node 1 is the mobile node $(\mathrm{AMN})$, the $\mathrm{AN}_{\mathrm{B}}$ node is marked with number 2, and the $\mathrm{AN}_{\mathrm{C}}$ node is marked with number 3 .

Fig. 2 shows the sequence of messages through which AMN node registration is achieved before the AMAP node. In this Fig. 2, when the AMN node is within the cover-age area of $\mathrm{AN}_{\mathrm{B}}$ node, it receives a warning message MIPT_ADS, containing the Care-of-Address (CoA) of $\mathrm{AN}_{\mathrm{B}}$ and the AMAP node address. Then, the AMN node registers with the AMAP node formulating a message MAP_REG_REQUEST through the $A M N>\mathrm{AN}_{\mathrm{B}}>\mathrm{AN} 2>$ AMAP route [6].

Fig. 3 shows the sequence of messages that allow the AMN node to register before the AHA node, which follows a similar registration process. At $\mathrm{t} 3$, the AMN node is in point 3 , and it is necessary to reconfigure the path, which will become $\mathrm{ACN}>\mathrm{AHA}>\mathrm{AN} 1>\mathrm{AMAP}>\mathrm{AN} 2>\mathrm{AN}_{\mathrm{C}}$. In this circumstance, the ANB node becomes the Ad Hoc Previous Router (APAR) and the ACN node becomes the Ad Hoc New Router (ANAR). According to this convention, the path is specified as $\mathrm{ACN}>\mathrm{AHA}>\mathrm{AN} 1>\mathrm{AMAP}>\mathrm{AN} 2>\mathrm{ANAR}$. The reason why node AMAP, becomes pivotal point for reconfiguration of the path is evident. 


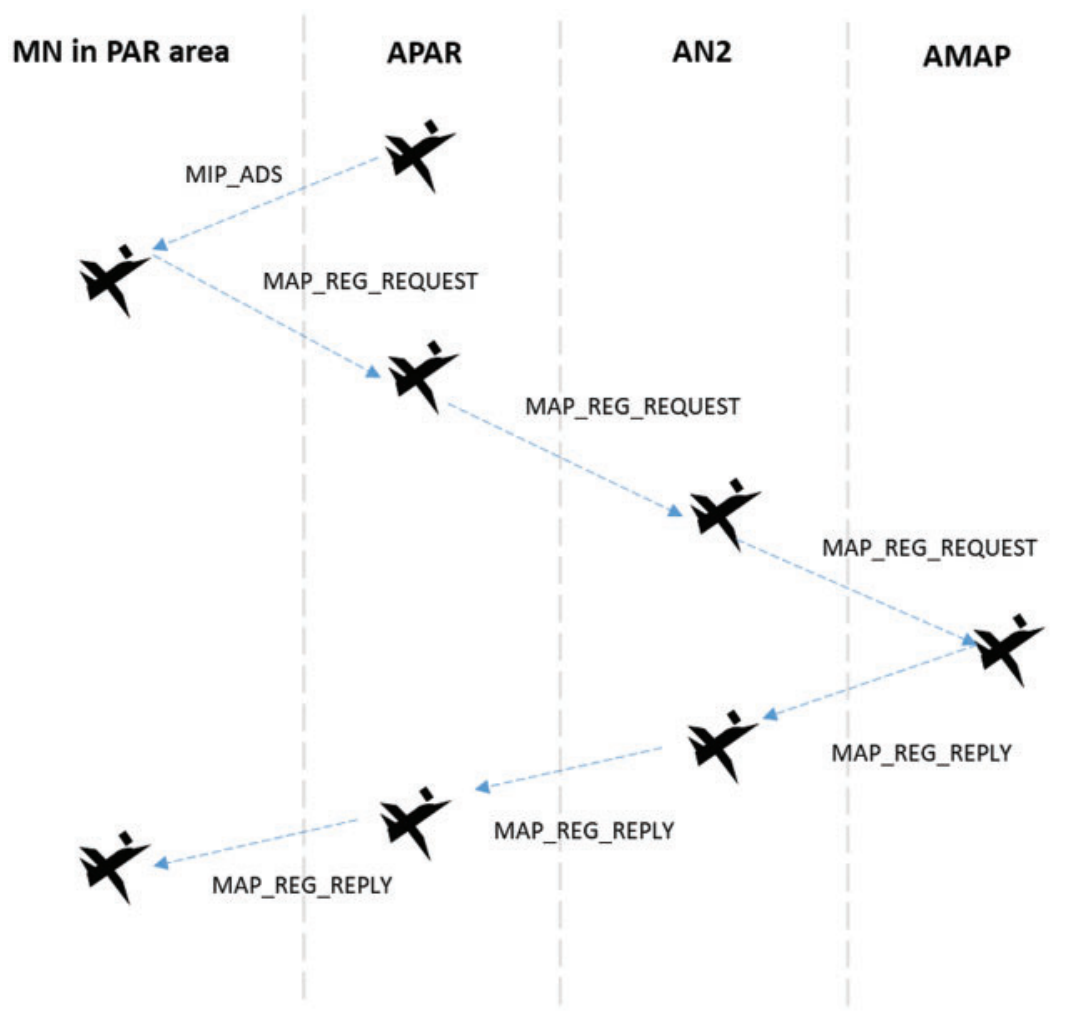

Figure 2: Sequence messages for registering AMN node-01

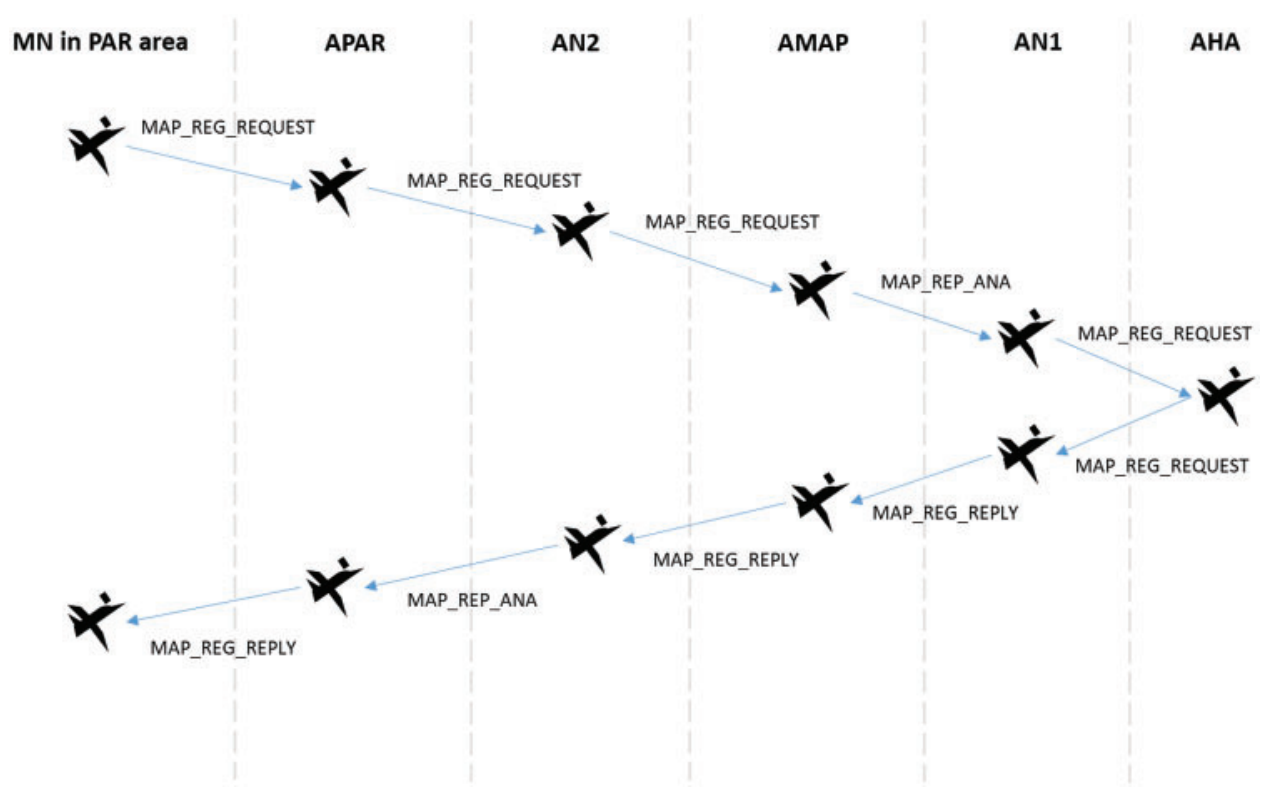

Figure 3: Sequence messages for registering AMN node-02 
CMC, 2022, vol.72, no.1

Fig. 4 shows the scenario with the conventions (node names) taken.

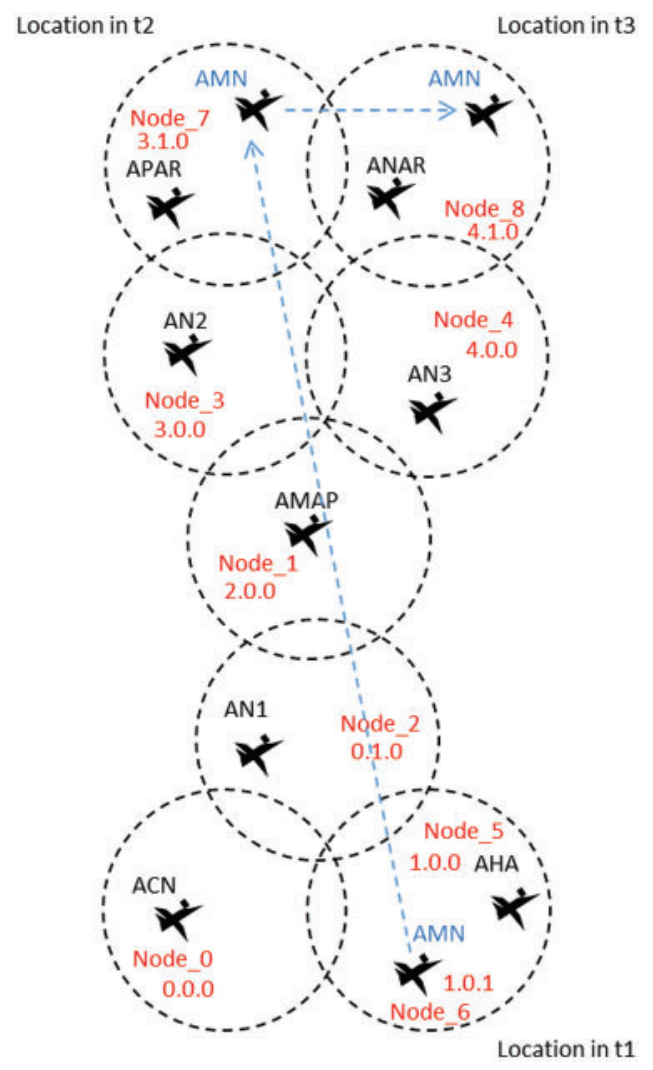

Figure 4: Reference scenario with AMN location

Fig. 5, shows the sequence of messages that are generated when the AMN node approaches ANAR node coverage area, coming from the coverage area of the APAR node. Initially, the AMN node sends a start message of Fast Handover, the FAST_RTSOLPR message, to the APAR node. Then, APAR node responds with a FAST_PRRTADV message indicating the direction of ANAR node. Then the registry process with the AMAP node is performed, such as described above, with the difference that now the path to the AMAP node is AMN > ANAR > AN3 > AMAP. Finally, MIPT_NA and MIPT_NACK messages are exchanged between the AMN and the ANAR nodes to indicate that the AMN node is completely in ANAR's node area, that is, there has been a complete level two handover.

Fig. 6 illustrates the registration between the AMN node and its AHA node, from ANAR's node coverage area.

It is necessary to have the cooperation of intermediate nodes between the previously mentioned nodes and the AMAP node. It is therefore necessary to discover these nodes [7].

Other hand, the register process can be analyzed as graph.

Fig. 7 shows the process through which the FHAMIPv6 protocol implements this task. 


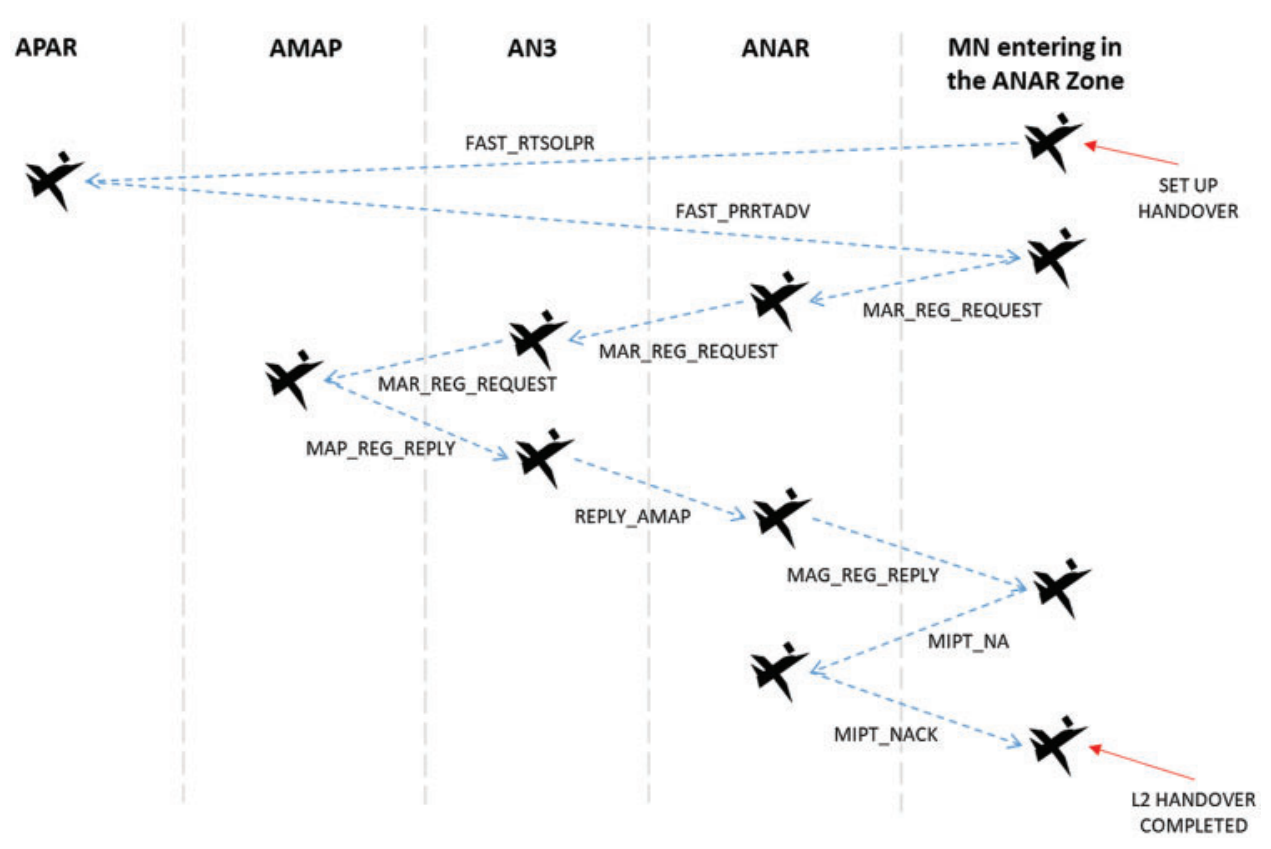

Figure 5: Events sequence in handover process

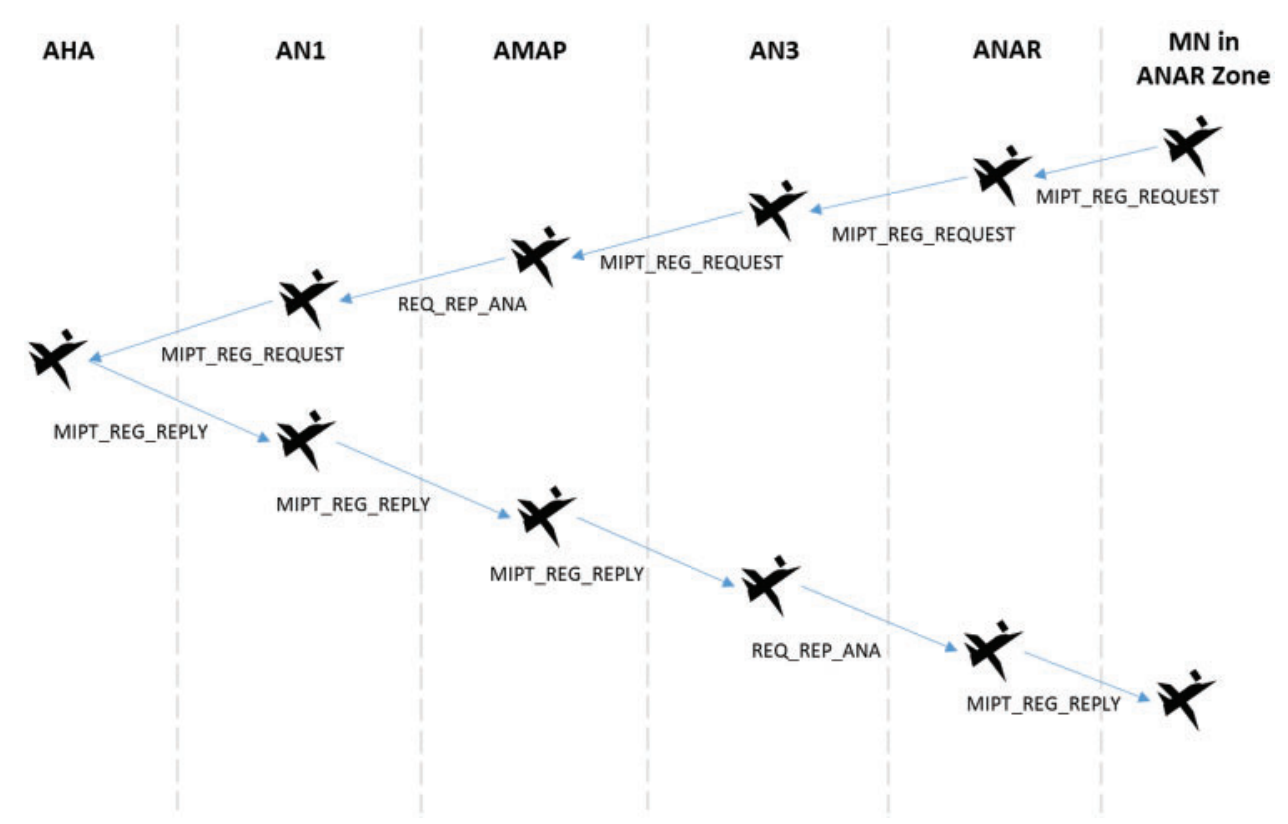

Figure 6: Registration between the AMN nodes 


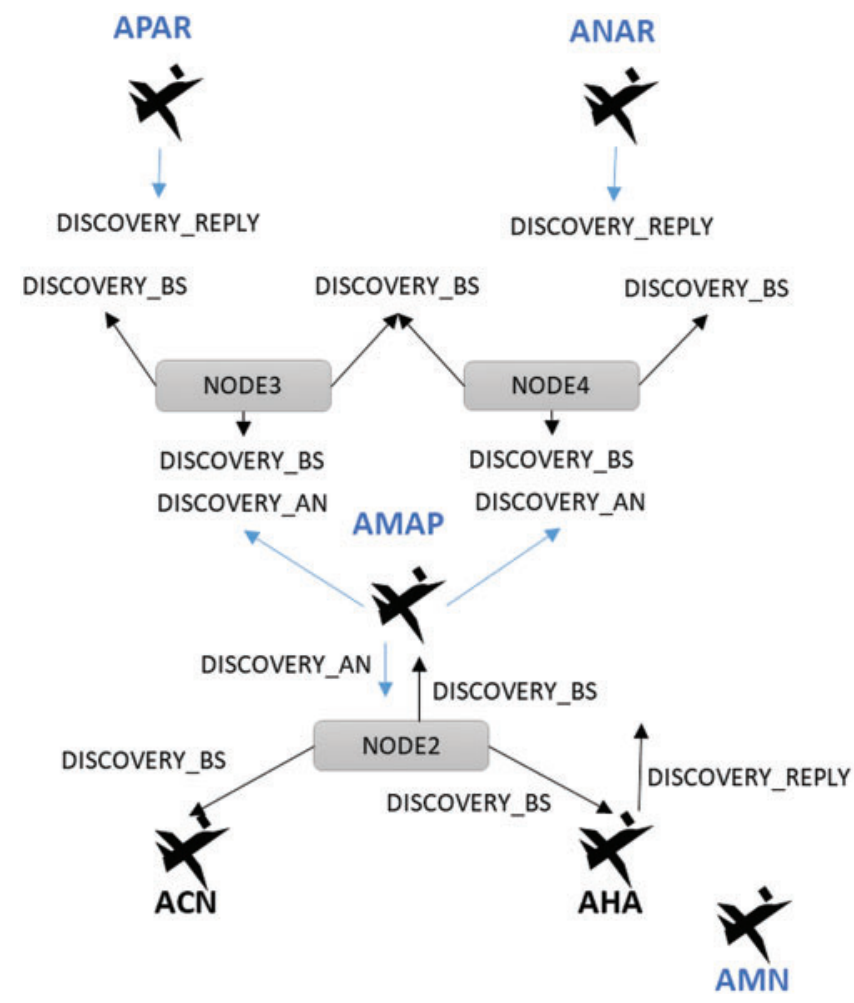

Figure 7: Node discovery process in FHAMIPv6

In this article, our proposal has an all IPv6/MPLS approach considering the standard quality of services protocols such as MPLS and the FHAMIPv6 extension meant to provide hierarchical addresses in an ad hoc network [1,3,4]. Is very important highlight that FHAMIPv6/MPLS has been created in order to provide quality of service in a mobile ad hoc network. The integration was designed as a mechanism that solve the Binding Update (BU) problem when a handover take place in the hierarchical mobile IPv6/MPLS (HMIPv6/MPLS) integration. In this period of time, there could be security and quality of service problems. With respect to the security, malicious message can be sent or received, regarding the quality of services; with respect to quality service, the signaling load can significantly degrade the evaluate QoS metrics. The FHMIPv6/MPLS integration will be avoid these problems [8].

In another hand, the most important in this paper is fast hierarchical mobile IPv6/MPLS (FHAMIPv6/MPLS) integration in order to provide quality of services (QoS) in wireless and hybrid ad-hoc networks, we test with FHMIPv6/MPLS in order to provide QoS in wireless ad hoc networks but was impossible use this FHMIPv6/MPLS integration by the characteristics of the network.

For this reason, was necessary modify FHMIPv6 protocol in order to work in mobile ad hoc scenarios. The proposal created is called Fast Hierarchical ad-hoc mobile IPv6 (FHAMIPv6) to see back-ground. The problem is that FHAMIPv6 protocol was created in order to work in ad hoc networks but, it is being not created in order to provide quality of service in mobile ad-hoc networks. For this reason, we integrate FHAMIPv6/MPLS to achieve quality of service in wireless ad hoc networks [9]. 
In order to achieve the target (Provide quality of service in ad hoc networks), was necessary create hierarchical mobile node with support MPLS and FHAMIPv6 protocols; in the ingress, intermediate and border nodes. Too, it was created the FHAMIPv6 agent with object to help: the routing, signaling and Quality of services (QoS) protocols in the communication source to destination. This FHAMIPv6 agent help to optimize: message process, discovered and establishment route, sending data in the ad hoc mobile networks, etc.

\subsection{Research Work}

The main idea of this preliminary work/simulation is to offer a vision of the quality of service in a real prototype of a drone swarm (Fly ad hoc networks), in order to optimize the quality of service at the network level. The defined parameters will allow you to adjust the metrics in a real environment.

Once satisfactory results have been obtained, mathematical models that will give a vision of the quality of the user experience based on the QoS metrics used in the simulation will be used.

In the simulation, swarms of 10, 20, 30 and 40 drones were used. From the experience of the group of researchers and the scalability property, it is known that if it works with this number of drones, it will also work with a number greater than or equal to 40 . Therefore, it is not necessary to increase the number of nodes in the simulation.

For model generalization, a function that shows the behavior of the metric was built.

The current need and its future trend is to provide drone swarm services with the next level of services (basic, medium, advanced and plus) focused on the agriculture, environment and civil works sectors, with an optimal quality of services (QoS), that manages to offer video and audio services, to provide a high degree of satisfaction to the final customer.

Highlight that FANET network, is each node is a drone connected wirelessly to the other nodes. The nodes are hierarchical MPLS that allow to use the extension of IPv6, FHAMIPv6, the integration of the protocol MPLS and HMIPv6 has been thought with the purpose of providing quality of services in fly ad hoc network (FANET). The FANET network has a central node (AMAP) that acts as a gateway and another series of nodes that can communicate between them.

This type of communications is modular and can be formed by multiple layers, including the capacity to identify nearby drones with which it has coverage in the communications network, as well as to know the size of the swarm, in the same way the capacity to make statistics and to authenticate itself in the network and to distribute this information among all its drones. This architecture is adaptable to different configurations depending on the flight mission and integrate it with bio-inspired algorithms depending on the task to be performed by the swarm.

Drone swarms are a model in which the set of units with a high degree of autonomy and few individual activities are able to coordinate to promote and carry out complex work and to a higher degree than each unit is available to do individually.

From the point of view of coverage, it is a few kilometers long, so a maximum of 40 drones have been used that serve as transmitters and receivers in ad hoc flight networks and that allow communication between the different nodes, terrestrial communication that provides connectivity to the swarm is a $5 \mathrm{G}$ network with low latency and excellent throughput.

This type of architecture is valid for different configurations and it is not necessary a manual network establishment or a manager that is constantly managing the swarm. 
This document is organized as follows: 1. Introduction, 2. Reference Architecture, 3. Scenarios and Quality of Services, 4. Discussion and Analysis of Results, 5. Security, 6. QoS/QoE, 7. Current Status and future Trends: Swarm data Services, 8. Integrations 9. Conclusions.

\section{Reference Architecture}

To get a better understanding of the solution formulated here. In Tab. 1, the typical configuration of a mobile node (drone) in the FANET is presented using the OSI reference model.

Table 1: FANET node architecture

\begin{tabular}{lll}
\hline Higher layers & \multicolumn{2}{c}{ Swarm data services/application } \\
\hline Network layer & Data plane & Control plane \\
\cline { 2 - 3 } & \multicolumn{2}{c}{ FHAMIPv6 } \\
& IPv6 & MODV \\
& MPLS \\
\hline Data link layer & 802.11ac \\
\cline { 2 - 3 } & \multicolumn{2}{c}{ MPLS } \\
\hline Physical layer (Wireless physical medium)
\end{tabular}

From bottom to top, on the physical level, there is the wireless medium through which the signal is physically spread from one drone to another; the data link level, and for the testing made in this article, the IEEE 802.11 ac protocol is used on the Medium Access Control (MAC) [10]. In addition, in this layer the MPLS label switching protocol component will be active once the quality of service path has been established; at the network level in the data plane, IPv6 is used as the network protocol, and control plane, the following protocols will be used: AODV as the routing protocol, FHAMIPv6 to improve efficiency in handover, and MPLS to establish source-destination paths with quality of service; finally, in the upper levels of each mobile drone's architecture the applications or services that have different quality of service requirements will be accommodated.

\section{Scenarios and Quality of Services}

\subsection{Metrics}

This section describes the most important events in the simulation, the movements of the (FANET node) AMN are shown, the instants of reserve of resources by Resource Reservation Protocol (RSVP) and some comments on the handover. It is important to mention that for the scenario of a variable number of drones (10, 20, 30 and 40), a File Transfer Protocol (FTP-type) traffic is used and the following QoS metrics are defined: Delay, jitter, throughput, Transmission Control Protocol (TCP) congestion window and dropped packets. These metrics are chosen because they are the most affected when occur a handover, in addition they are the metrics that most significantly affect the traffic with higher QoS requirements such as: video, audio and real-time applications.

The Fig. 8 scenario proposal by Robert Hsieh in FHMPv6. 


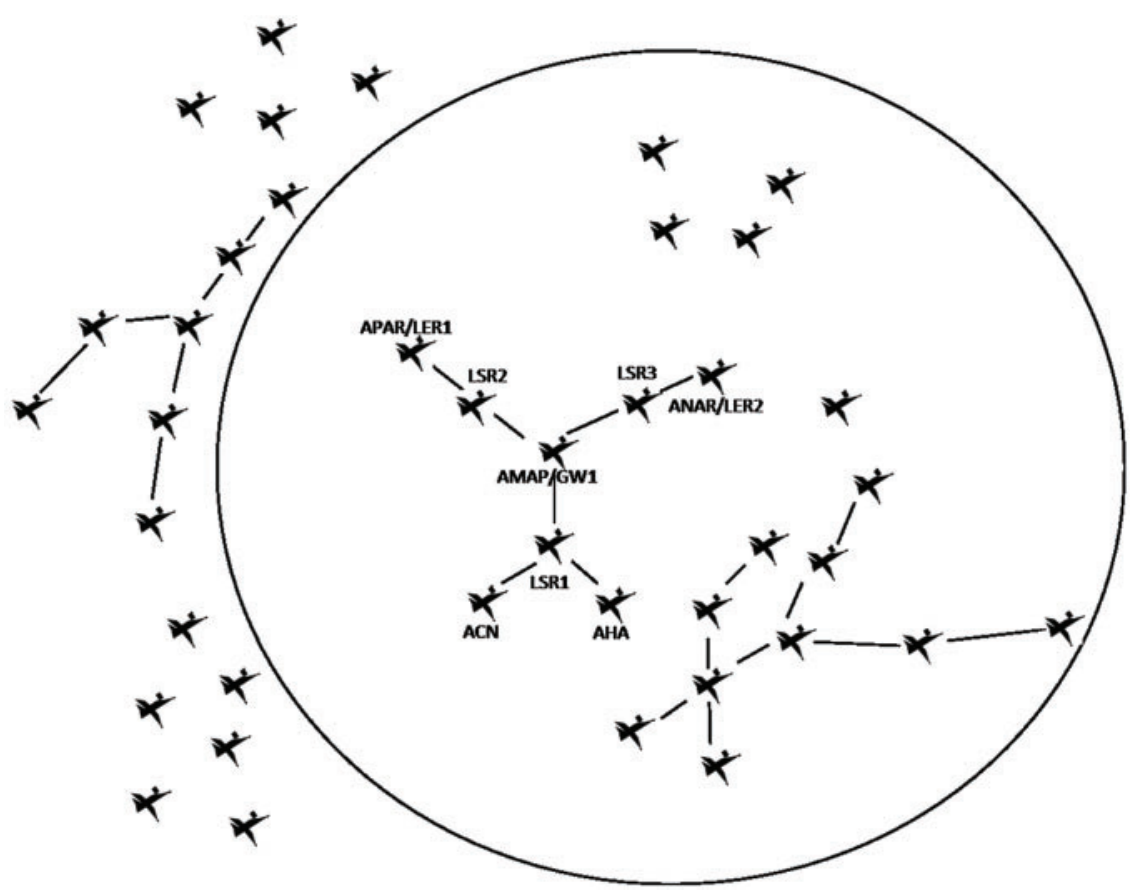

Figure 8: Scenario FANET

The Fig. 9 illustrates the simulation scenario with 40 nodes, it describes an environment of macro mobility, since the access routers are in different domains.

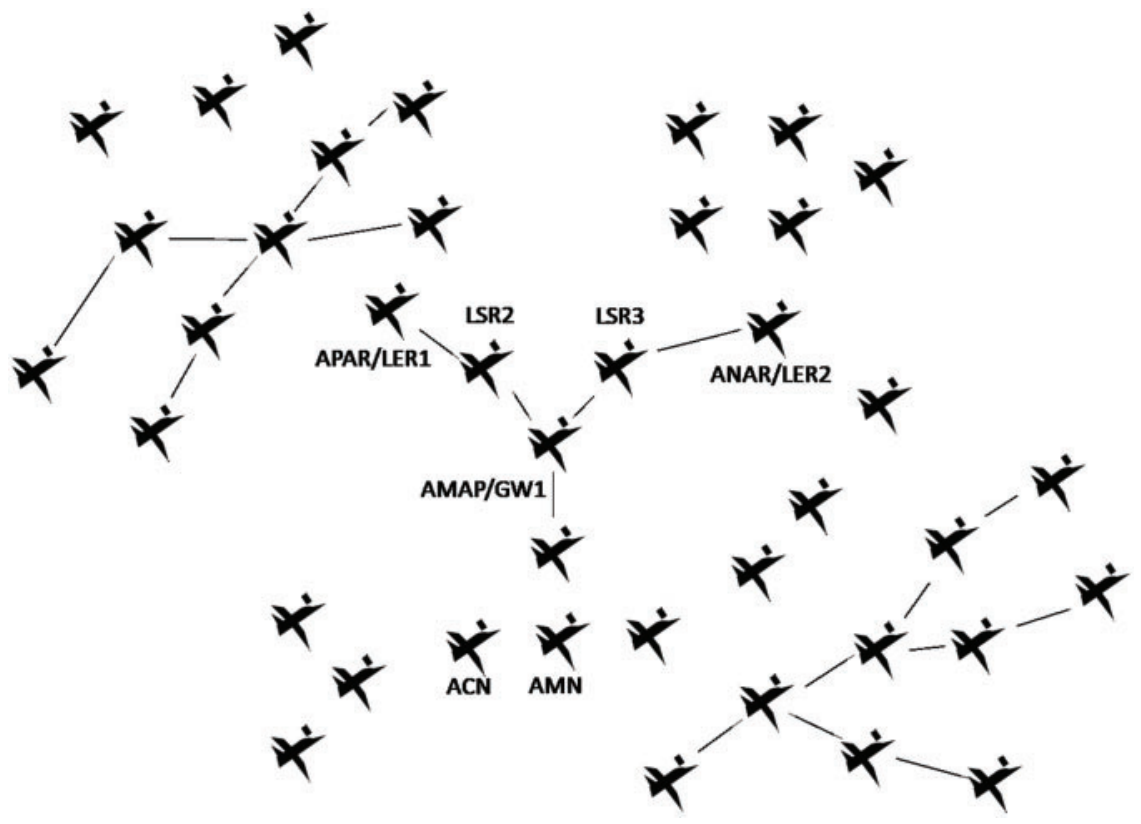

Figure 9: Initial scenario of 40 nodes 
Regarding the scalability of integration (FHAMIPv6/MPLS) scenarios with different number of nodes were simulated, to assess the impact of the behavior of the proposed integration (FHAMIPv6/MPLS) on the QoS metrics and the functionalities in different scenarios with different number drones. In another hand, Network Simulator (NS) the tool used to simulate ad hoc scenario. The biggest problem in ad hoc networks is scalability. Analyze the scalability in wireless and hybrid ad hoc networks. The problem by the characteristic of the network are: the topology, nodes mobility, connection and disconnection, establishment routes, actives and not actives nodes, etc.

A. Discussion and simulation description of the scenario of 40 nodes:

In the beginning, the FANET node is in the area of its home agent (AHA) as shown in Fig. 2, subsequently in $t=1,2 \mathrm{~s}$, the AMN initiates the transfer of FTP traffic with the ACN, then between $\mathrm{t}=3,5 \mathrm{~s}$ and $\mathrm{t}=4,5 \mathrm{~s}$ reservation of MPLS/RSVP resources is completed in the path MAP Network Gateway $(\mathrm{MAP} / \mathrm{GW} 1)>\mathrm{LSR} 2>\mathrm{PAR} / \mathrm{LER} 1$. At time $\mathrm{t}=5 \mathrm{~s}$, the AMN is directed towards node 1 at a speed of $100 \mathrm{~m} / \mathrm{s}$, arriving at this position a few instants later as shown in the Fig. 10.

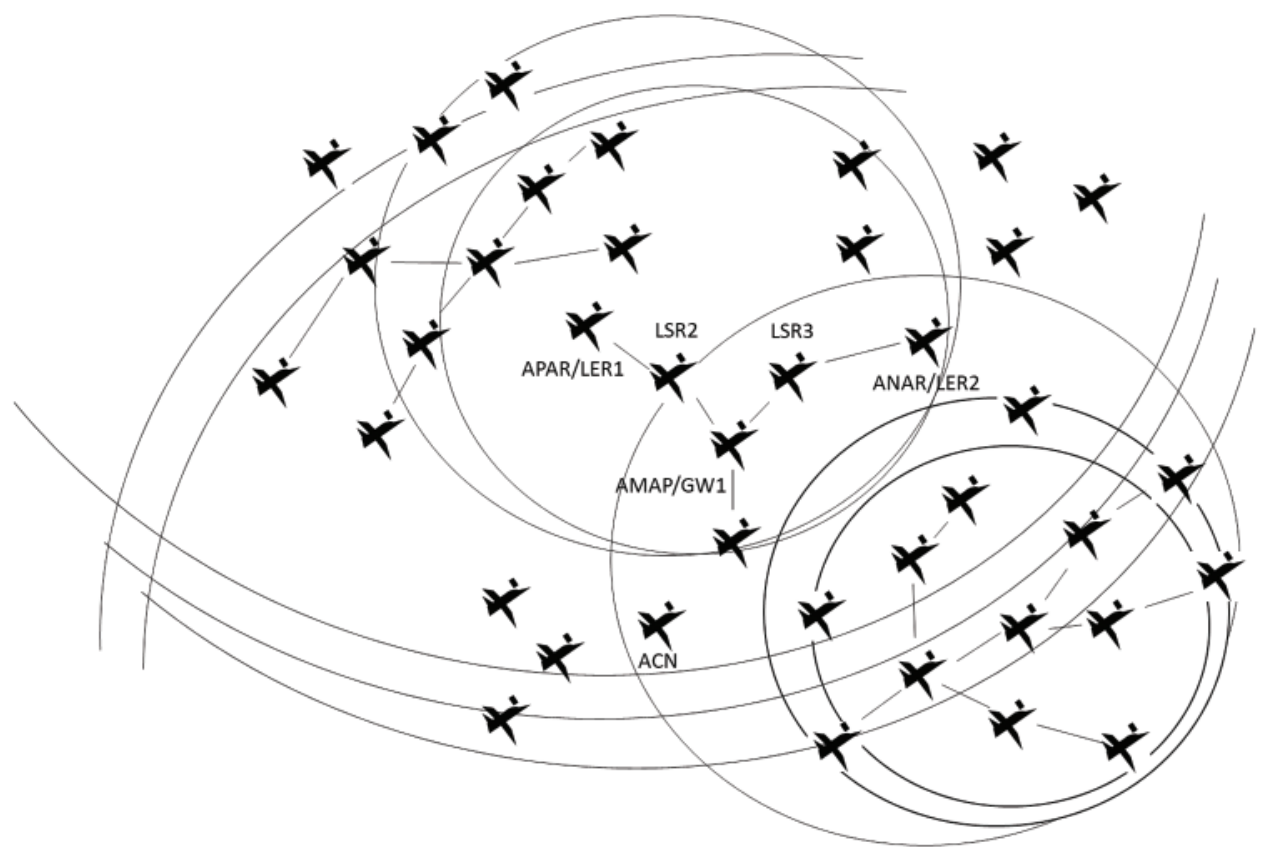

Figure 10: $A M N$ in node 1 zone, scenario of 40 nodes

Later, at time $\mathrm{t}=9 \mathrm{~s}, \mathrm{AMN}$ begins its displacement towards the PAR/LER 1 at a speed of $100 \mathrm{~m} / \mathrm{s}$ shortly after reaching this zone from which will onwards use the PAR/LER1 > LSR2 > AMAP/GW1 $>$ AN1 route to communicate with the ACN and the AHA. Fig. 11 illustrates this displacement.

Then, between $t=14,5$ and $t=15,5 \mathrm{~s}$, resource reservation takes place in the MAP/GW $1>$ LSR 3 $>$ NAR/LER 2 route anticipating the following handover performed by the AMN. It travels at $10 \mathrm{~m} / \mathrm{s}$ from PAR/LER 1 towards NAR/LER2 at $\mathrm{t}=20 \mathrm{~s}$. Henceforth, the traffic will travel through the route NAR/LER > LSR3 > MAP/GW1 > AN1 to communicate with the ACN and the AHA. This is illustrated in the Fig. 12. 


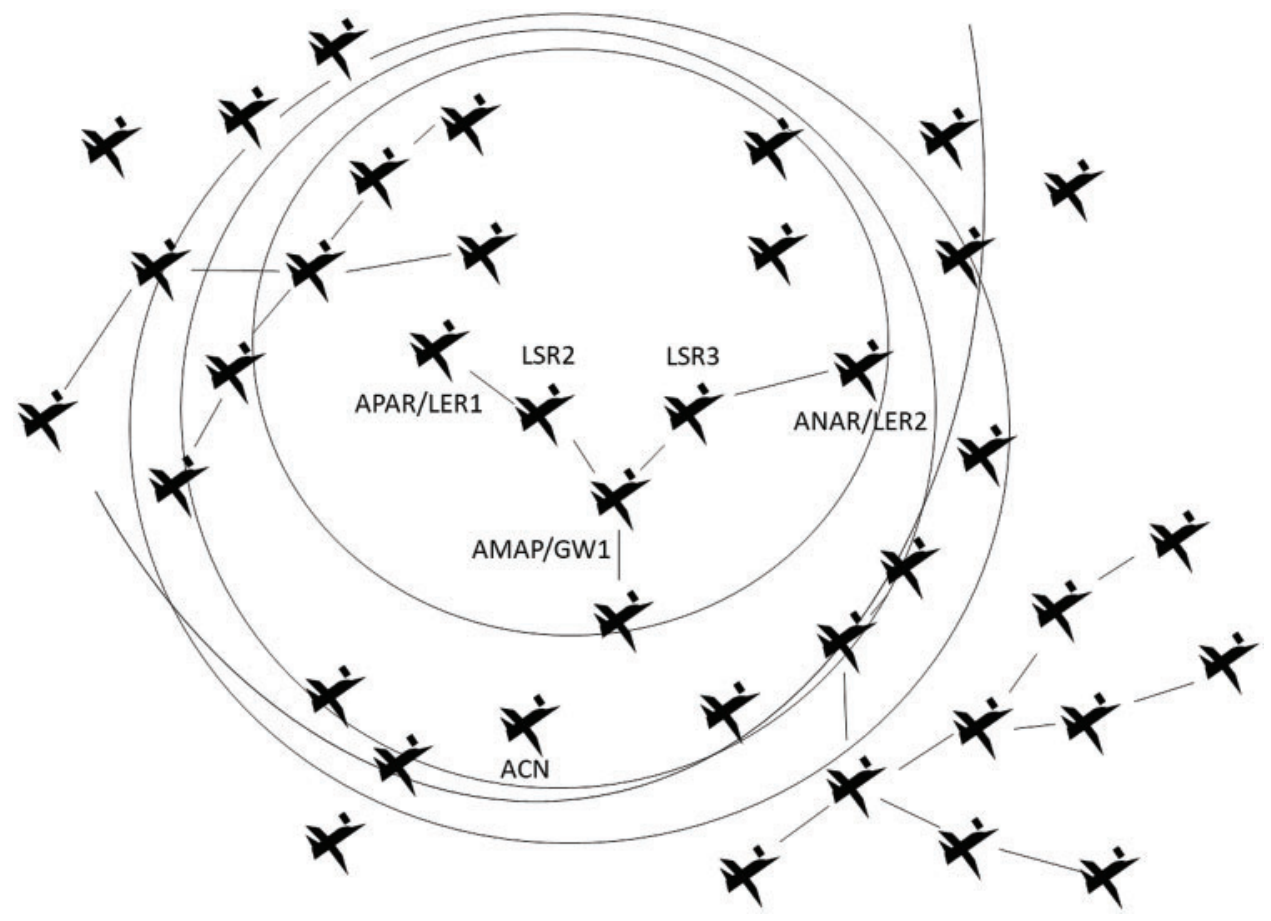

Figure 11: AMN in PAR/LER1 zone, scenario of 40 nodes

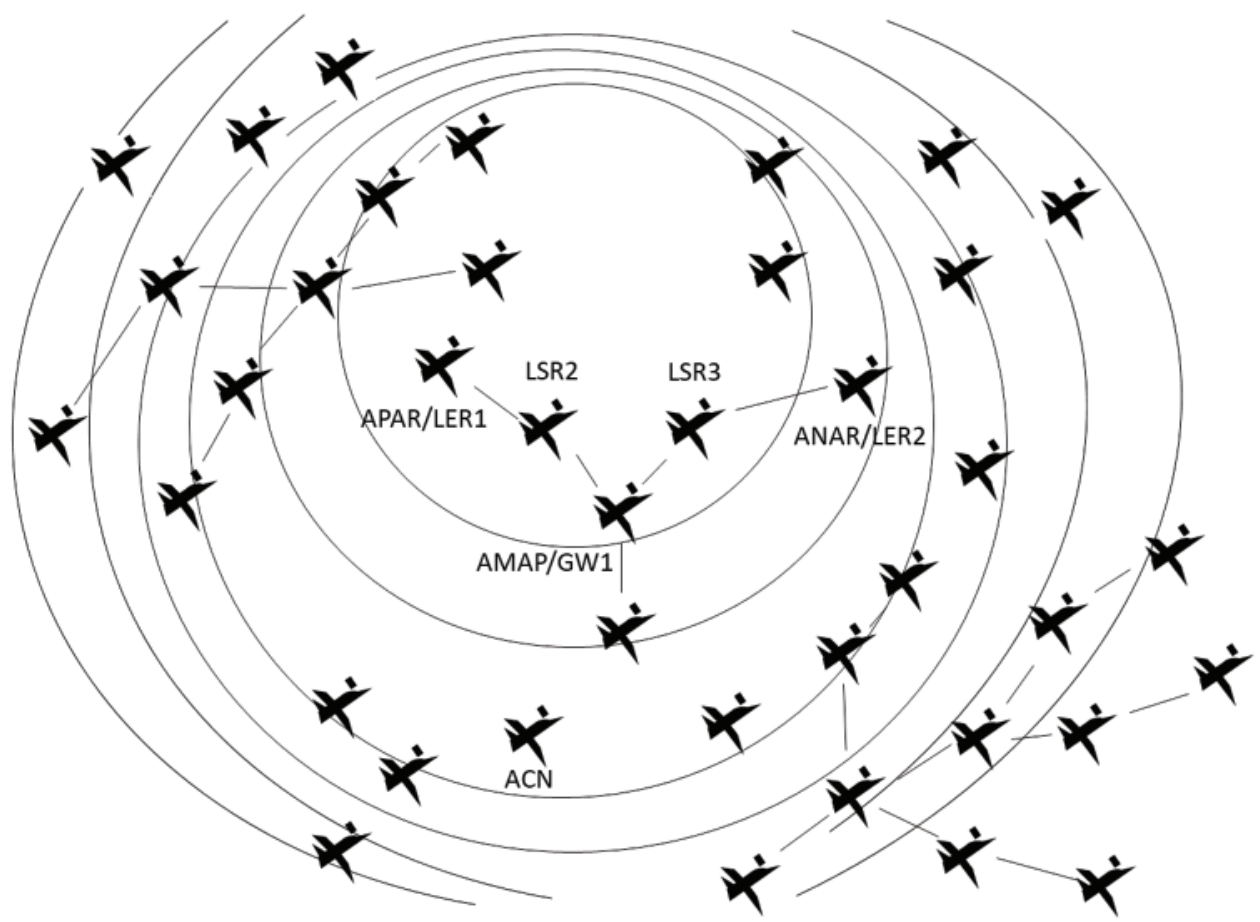

Figure 12: AMN in PAR/LER1 zone, scenario of 40 nodes 
Finally, the simulation ends at time $\mathrm{t}=40 \mathrm{~s}$, moment when FTP traffic stops. Traffic flows used in the simulation are summarized in the following Tab. 2, see below.

Table 2: Summary of the traffic flows in the simulation of 40 nodes

\begin{tabular}{lllll}
\hline Source drone & Destination drone & Type of traffic & Initial time & Final time \\
\hline AMN & ACN & FTP & 1.2 & 40.0 \\
ADN6 & ADN8 & CBR & 2.0 & 5.0 \\
CN13 & CN12 & CBR & 3.0 & 5.0 \\
CN10 & AN2 & CBR & 5.0 & 9.0 \\
ADN5 & ADN7 & CBR & 10.0 & 12.0 \\
CN6 & CN7 & CBR & 12.0 & 15.0 \\
CN11 & AN3 & CBR & 16.0 & 17.0 \\
CN2 & AN2 & CBR & 17.0 & 19.0 \\
CN8 & AN1 & FTP & 30.0 & 32.0 \\
CN1 & AN1 & CBR & 33.0 & 36.0 \\
CN3 & AN3 & CBR & 37.0 & 40.0 \\
\hline
\end{tabular}

Notes: Correspondent Node (CN), Ad Hoc Node (AN), Constant Bit Rate (CBR), Autonomous drone navigation (ADN), ad hoc mobile node (AMN), File Transfer Protocol (FTP), Ad Hoc Correspondent Node (CAN).

\section{Discussion and Analysis of Results}

This section presents the results of the simulations in terms of QoS metrics for the simulated scenario. It is noteworthy that all metrics are evaluated from the perspective of the AMN.

Fig. 13 illustrates the behavior of the delay as time passes in the simulation.

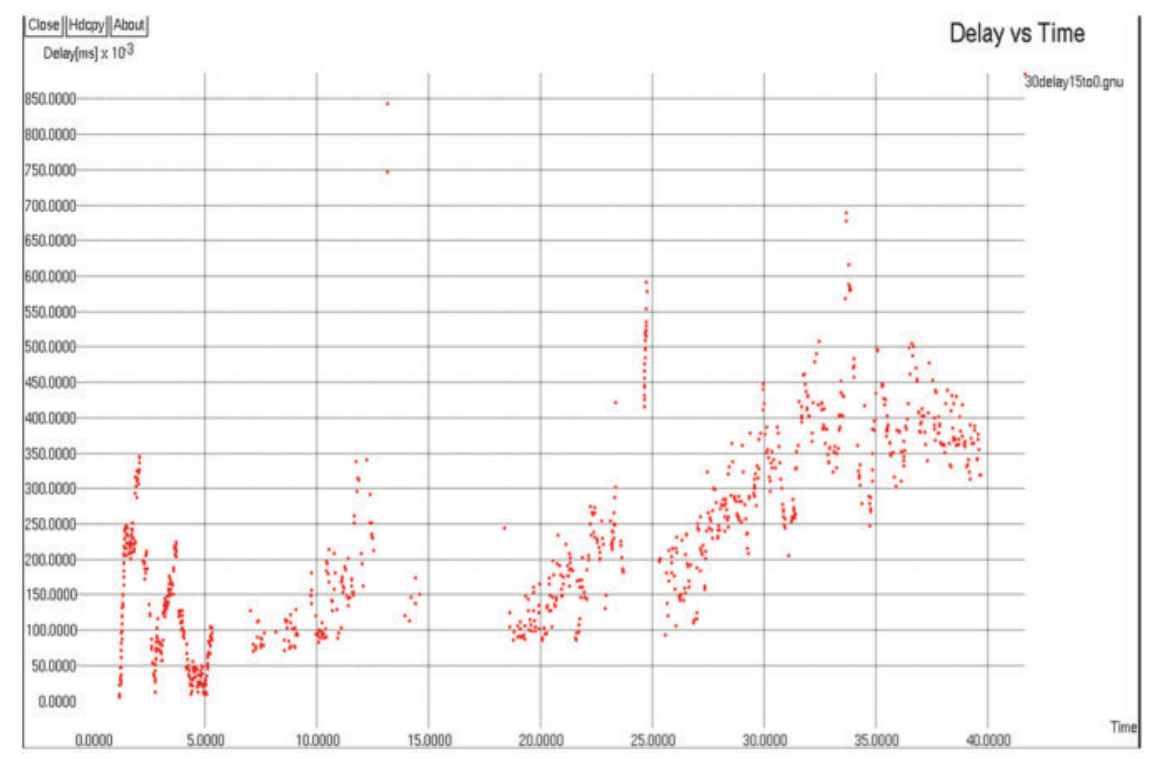

Figure 13: Delay $v s$. time, scenario of 40 nodes 
As illustrated in the Fig. 13, in the first $5 \mathrm{~s}$ of simulation, a large amount of traffic is transferred. This volume of traffic is not affected significantly although 2 additional simultaneously traffic flows circulate the network. Subsequently, at $\mathrm{t}=5 \mathrm{~s}$ AMN moves to node 1 where it stays showing a similar behavior to the initial until time $t=9 \mathrm{~s}$ where it begins its movement toward the PAR/LER1, when the AMN node reaches the above-mentioned area (PAR/LER1), the behavior of the delay changes significantly due to the existence of four traffic flows in the network.

However, the delay does not exceed $850 \mathrm{~ms}$ despite the high congestion. Later, at $\mathrm{t}=20 \mathrm{~s}$, the AMN node starts to move towards ANAR/LER2 when appears a peak of almost $600 \mathrm{~ms}$ near time $\mathrm{t}=25 \mathrm{~s}$. Thereafter the experienced delay slightly increases up to a maximum of about $700 \mathrm{~ms}$ near time $\mathrm{t}=34 \mathrm{~s}$ and then shows a decrease even though there is another traffic flow on the network in the range between $\mathrm{t}=37$ and $\mathrm{t}=40 \mathrm{~s}$. The average delay in the simulation is $225,517 \mathrm{~ms}$.

\subsection{Analysis of Jitter}

Fig. 14 illustrates the behavior of the jitter vs. time. Its behavior along the simulation is not homogeneous as shown in Fig. 13. Initially, when the AMN node (drone) in AHA's area there's a very small and dense fluctuation affected minimally by two simultaneous traffic flows traversing the network. Subsequently, when the AMN node moves to node 1 , in $t=5 \mathrm{~s}$, the amount of packets transmitted decreases significantly, which is reflected in the decrement of density of these packets (see the Fig. 13). After, when AMN node is making its movement towards the PAR/LER1 zone, the number of transmitted packets in-creases, while recording the highest peak of about $360 \mathrm{~ms}$ close to $15 \mathrm{~s}$ after the beginning of the simulation.

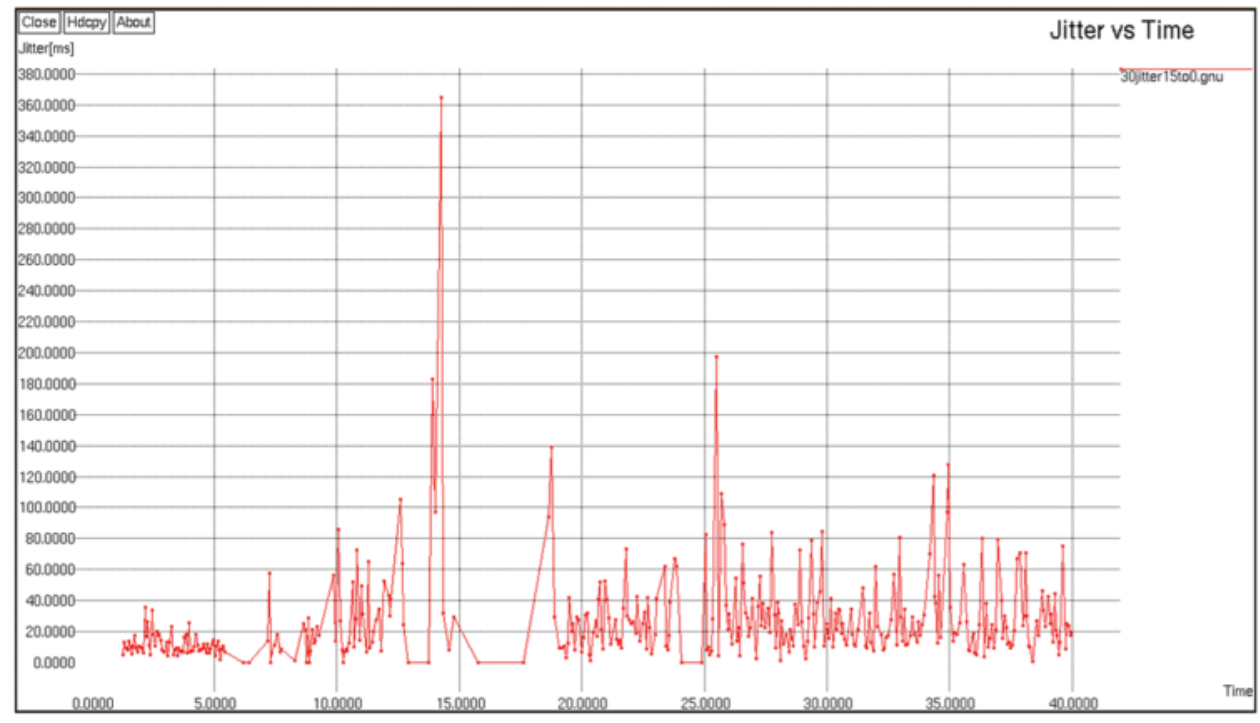

Figure 14: Jitter vs. time, scenario of 40 nodes

The presence of two traffic flows around that moment may be the cause of the mentioned peak. In addition, in $\mathrm{t}=20 \mathrm{~s}$ the AMN node starts to move towards ANAR/LER2, this fact has no implications on the jitter up to $t=25 \mathrm{~s}$ where the handover is completed, then shows a slight peak in the jitter. 
Subsequently, the jitter shows a homogeneous behavior with slight alterations due to the overload of the network in the moments close to the $35 \mathrm{~s}$ after the beginning of the simulation. Finally, the average jitter was 21, $9942 \mathrm{~ms}$.

\subsection{Throughput Analysis}

Fig. 15 illustrates the throughput performance as time elapses. It shows that the throughput is high at the moment when the AMN node is in the AHA area before its first displacement at $\mathrm{t}=5 \mathrm{~s}$, after this there are marked fluctuations when the AMN is located in the 1's node, then in $t=9 \mathrm{~s}$, it moves to PAR/LER 1 and affects the throughput significantly by the presence of two flows that add overload to the network; however, at times the throughput reaches values close to $600 \mathrm{Kbps}$. The same as with the other metrics, the throughput is affected when the handover is completed at about $25 \mathrm{~s}$ once the AMN node starts to drift towards the ANAR/LER2. Afterwards, it shows a regular behavior de-spite three major traffic flows circulating in the network at that time. It can be see that the average throughput in the simulation was $206.865 \mathrm{Kbps}$.

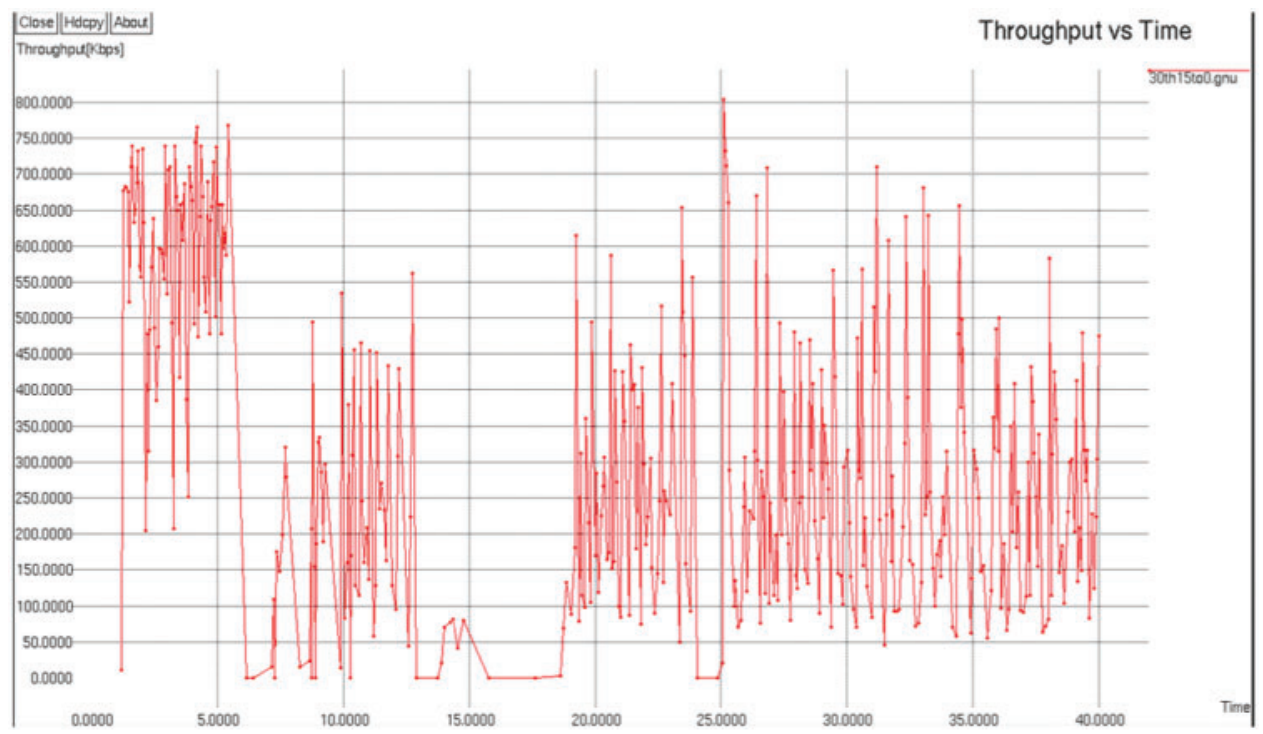

Figure 15: Throughput vs. time, scenario of 40 nodes

The moments when the throughput declines to $0 \mathrm{KBps}$ is due to the packet loss, this can be verified in the Fig. 16 that shows the TCP congestion window vs. time, it is shown below.

- Analysis of lost packets

During simulation, 989 packages were sent from AMN node towards the Controller Area Network (CAN) node, from which 955 arrived at its destination, resulting in the loss of 34 packets, which corresponds to $3.44 \%$ of packets.

- Analysis of results

Tab. 3 below, summarizes the results obtained during the simulation of different scenarios. 


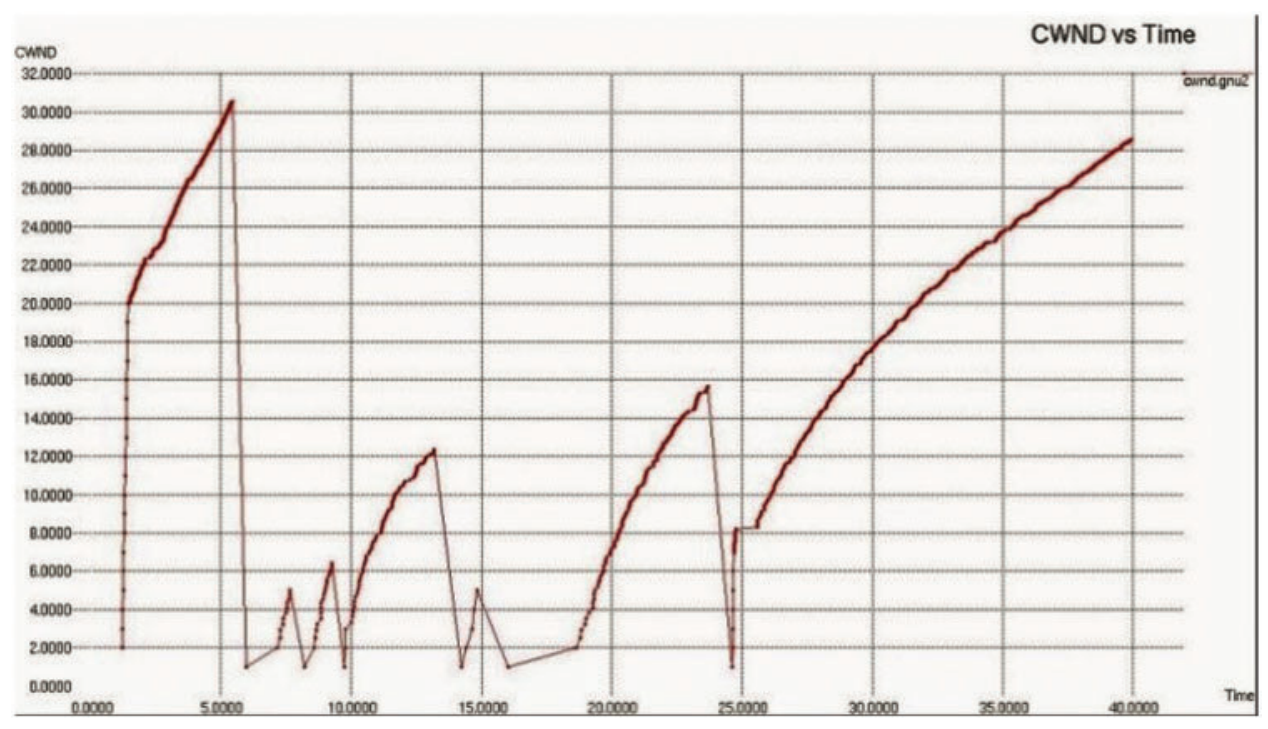

Figure 16: TCP congestion window vs. time, scenario of 40 nodes

Table 3: Node numbers vs. metrics of quality services (QoS)

\begin{tabular}{llllll}
\hline Nodes & Delay $(\mathrm{ms})$ & Jitter $(\mathrm{ms})$ & Throughput $($ Kbps $)$ & Packet send & Packet loss \\
\hline 9 & 224.5 & 15.8 & 343.7 & 1160 & 24 \\
15 & 252.3 & 25.5 & 241.3 & 1160 & 40 \\
20 & 275.1 & 27.9 & 241.6 & 1160 & 53 \\
25 & 250.1 & 25.6 & 232.4 & 1160 & 44 \\
30 & 222.5 & 22.0 & 206.7 & 1160 & 34 \\
40 & 170.6 & 17.6 & 202.5 & 1160 & 53 \\
\hline
\end{tabular}

\section{Security}

\subsection{Security in FHAMIPv6}

Security requires special attention in the context of FANETs. The flooding attacks can cause a collapse in services and exhaust computational and power resources in mobile nodes; identity theft and information modification can lead to routing table's contamination causing the malfunction of the entire network. Therefore, it is necessary to make a reflection about security in these networks (FANET) and upon the occurrence of such events (handover) [11].

For this reason, multiple at-tacks can be carried out against this protocol. Some of which can cause anything from a simple network delay up to its complete collapse. Tab. 4 summarizes the types of attacks that involve manipulating FHAMIPv6 messages.

In addition to the FHAMIPv6 security problems, there are others like the access protocol to the medium used (IEEE802.11), therefore the risk to which the information is exposed, increases. 
Table 4: Summary of the FHAMIPv6 security issues

\begin{tabular}{ll}
\hline Manipulated message & Consequence \\
\hline MIPT_ADS & $\begin{array}{l}\text { Confidentiality lost, data } \\
\text { modification, denial of service }\end{array}$ \\
MAP_REG_REQUEST and & $\begin{array}{l}\text { Denial of service to the AMN } \\
\text { node }\end{array}$ \\
MAP_REG_REPLY & Confidentiality lost, data \\
MIPT_REG_REQUEST and & modification, denial of service \\
MIPT_REG_REPLY & $\begin{array}{l}\text { Confidentiality lost, } \\
\text { communications delay of the } \\
\text { FASTPRRTADV }\end{array}$ \\
& AMN node increase. \\
& Network collapse \\
DISCOVERY_REPLY &
\end{tabular}

\subsection{Security Mechanisms}

In this work we talk about the security of the protocols that provide end-to-end QoS in the network, that means, the integration of the protocols security that provide QoS in the network, from the origin to the destination of the packages.

This paper has focused on video and audio transmission, because they are more sensitive and are also the most used services in this type of swarm. Therefore, the security of the integration depends on the compatibility of the integration and the security of each protocol at the layers application, transport, network, link and physical [12].

Contributions at the security level are: the results obtained with the integration of the protocols used (FHAMIPv6/MPLS) and the safety of each of the drones that are part of the swarm has also been taken into account.

\section{QoS/QoE}

The measurement of the quality of the experience has been carried out with the objective method Video Quality Metrics (VPM). As a consequence, there must be values for the quality of service parameters (delay, jitter, and packet loss) that allow the best response of the quality of experience associated with the video (measured with an objective method). Video Quality Metric (VQM) was chosen because it is a standardized model, that uses little bandwidth and extracts data from source and destination videos.

The least squares method and the following quality of service parameters have been used in this paper: $\mathrm{D}=$ Delay, $\mathbf{J}=$ Delay variation and $\mathrm{PP}=$ Packet loss, etc. The measure of the quality of experience associated with video is identified as QoE [13].

$$
Q o E=\beta_{0}+\beta_{1} R+\beta_{2} V_{R}+\beta_{3} P_{P}+\beta_{4} R^{2}+\beta_{5} V_{R}^{2}+\beta_{6} P_{P}^{2}+\beta_{7} R V_{R}+\beta_{8} R P_{P}+\beta_{9} V_{R} P_{P}[14]
$$

\section{Current Status and Future Trends: Swarm Data Services (FANET)}

The result of the simulation in NS is very useful because it can be applied to a real environment. With the QoS results obtained in the simulation and the mathematical model, it will be possible to predictively evaluate QoE at network and user layers. The swarms will consist of four service layers 
and three sectors, the services will be business-to-business (B2B) and will be integrated with the Big Data platform to optimize service to the end customer, the sectors are: agriculture, civil works and the environment [15].

Let's see each of the service options in Tab. 5:

Table 5: Services, data analytics to obtain higher profit

\begin{tabular}{|c|c|c|c|}
\hline \multirow[t]{2}{*}{ Description } & \multicolumn{3}{|c|}{ Agricultural } \\
\hline & Basic & Medium & Pro \\
\hline Flight data management & Yes & Yes & Yes \\
\hline Swarm management & Yes & Yes & Yes \\
\hline Genetic algorithms & & & Yes \\
\hline Bee algorithms & & & Yes \\
\hline Ant algorithms & & & Yes \\
\hline Bird algorithms & & & Yes \\
\hline Molecular algorithms & & & Yes \\
\hline Mission planning & Yes & Yes & Yes \\
\hline $\begin{array}{l}\text { Budget management and } \\
\text { control }\end{array}$ & & & Yes \\
\hline Storage & & & Yes \\
\hline Administration tools & & & Yes \\
\hline Multimedia services & & Yes & Yes \\
\hline $\begin{array}{l}\text { Security, identity and } \\
\text { compliance }\end{array}$ & & Yes & Yes \\
\hline Machine learning & & & Yes \\
\hline Analysis & & & Yes \\
\hline Augmented and virtual reality & & Yes & Yes \\
\hline Application integration & & & Yes \\
\hline Business productivity & & & Yes \\
\hline $\begin{array}{l}\text { Streaming and desktop } \\
\text { application }\end{array}$ & & & Yes \\
\hline Cloud Iot & & & Yes \\
\hline Intelligent data analytics & & & Yes \\
\hline Reporting & & Yes & Yes \\
\hline Data driven decision making & & & Yes \\
\hline Backup & & Yes & Yes \\
\hline Image editing & Yes & Yes & Yes \\
\hline Pilot training & Yes & Yes & Yes \\
\hline Photogrammetry training & & Yes & Yes \\
\hline Rendering & & & \\
\hline Customisation & & & \\
\hline Other & & & Yes \\
\hline Personalization & & & Yes \\
\hline
\end{tabular}


Table 5: Continued

\begin{tabular}{llll}
\hline Description & \multicolumn{3}{c}{ Agricultural } \\
\cline { 2 - 4 } & Basic & Medium & Pro \\
\hline Refurbish & Yes & & \\
Multimedia services & & Yes & Yes \\
\hline
\end{tabular}

Specifically in agricultural sector the following can be seen.

Basic Service: it includes elements related with the swarm characteristics, control unit devices, and with the management of information and obtained data on each one of the missions, as well.

If we talk about the swarm's element, all our have the following characteristics: Dust and water proof, high-temperatures proof, rugged control screen, flight stabilization system, each drone has a $250 \mathrm{gr}$ of weight, High Definition (HD) camera system, with a resolution of $1080 \times 720$ pixels, sensor coverage of 180 grades, they can reach a maximum height of 40 meters, a speed-limit of $6 \mathrm{~m} / \mathrm{s}, 20 \mathrm{~min}$ of absolute flight autonomy.

As for the control unit, each swarm has been designed to fulfill a specific flight mission, which has to be previously programed directly from the control Unit. Each control unit contains algorithms inspired on pre-existing nature swarms, (known as bio-inspired), which facilitates the correct development of the mission, and improves the collective intelligence of each swarm. Just to mention some of the nature-based algorithms, there are genetically, and particle optimization-types alike. This specific type of services is focused on the analysis of farmlands, taking into account the variety of herbage which co-exists on each different zone [16].

Intermediate Services: The intermediate one includes the same elements which constitutes the basic service (swarm characteristics, control unit devices, management of in-formation and obtained data) with a few changes on the quality on each one [17].

On which swarm characteristics concerns, this specific service counts with a more efficient camera, with a resolution of $1920 \times 1080$ pixels, it can reach a better limit-altitude (60 meters), its faster, reaching $10 \mathrm{~m} / \mathrm{s}$, and doubles the flight autonomy, being capable to fly for about $40 \mathrm{~min}$ without the need of being controlled.

The control unit for these type of service counts with bio-algorithms inspired on the way different types of insect's works, such as bees and ants. This specific type of service is focused on the identification of the cultivation phases, and to carry out the counting and registration of the cultivation of plants and the amount of pesticides necessary to take care of their growth [18].

In terms of the management of the obtained data, this service allows to establish a medium level of scalability, the acquisition of a mash-up between the cloud and the dis-tributed architecture, and the storage of structured, and non-structured data, on a distributed platform.

Advanced Service: As the intermediate, and the basic service, the advanced service counts with the same kind of elements (swarm characteristics, control unit devices, management of information and obtained data) with some improvements and a better quality [19].

Swarm characteristics: all drones have the following characteristics: water and dust resistance, high temperature resistance, resistant control screen, flight stabilization, weight $200 \mathrm{gr} / \mathrm{drone}$, Ultra 
High Definition (UHD) $4 \mathrm{~K}$ camera, maximum flight coverage of 800 meters, sensor coverage of 360 degrees, a maximum speed of $20 \mathrm{~m} / \mathrm{s}$, flight range of 80 meters, and coverage of 80 meters.

Control unit: Unlike the two services described previously, the advanced service counts with all of the bio-algorithms mentioned (genetically-ones, particle differentiation, bees, and ants). This type of service is focused on the state of land, quantity of water and nutrients, inputs and quantities necessary for cultivation and soil sensors [20].

Tab. 6 shows the data analysis services generated by the swarm. This table is focused on customized services, in addition; to the list that appears in the pro or advanced level for agricultural sector. The table helps in the process of management and data analysis in each project for decision making of the final customer, and thus obtain a greater return on investment in the custom swarm [21].

Table 6: Agricultural sector services

\begin{tabular}{ll}
\hline Area & Agricultural \\
\hline Scalability on medium request & Yes \\
$\begin{array}{l}\text { Combination of cloud and distributed } \\
\text { architecture }\end{array}$ & Yes \\
$\begin{array}{l}\text { Virtualized data storage on platform } \\
\text { Structured and un structured data on distributed } \\
\text { platform }\end{array}$ & Yes \\
$\begin{array}{l}\text { Advanced data powered analytics functions } \\
\text { Obtainable accessibility }\end{array}$ & Yes \\
$\begin{array}{l}\text { Analytical capabilities derived from more } \\
\text { specifics algorithms }\end{array}$ & Yes \\
\hline
\end{tabular}

\section{Integration with IEEE 802.11ac}

So far, our discussion has been focused on the improvements that can be achieved from the network level regarding continuity and maintenance of the quality of service. The use of a reactive routing protocol (AODV), a protocol to ensure efficient transfer in FANET networks (FHAMIPv6) and the use of a protocol to establish paths with quality of service (MPLS). The efficient integration that ensures the described functionality, has been the focus of this article. However, this can only be possible to the extent that there is a correct and efficient integration with the media access control layer [22].

The MAC sub layer is responsible for characterizing the channel condition and service through continuous monitoring of events associated with mobility and tracking metrics that define their performance. It is intended to introduce a middleware layer between the media access layer (that depends on the technology) and higher levels, to generate a generic set of primitives that allow report, in a standard way, the performance metrics of the lower levels (physical and data link) and monitor the occurrence of events associated with the mobility that affects performance in FANET [23].

This layer, a software agent, ensures the sustainability of the formulated solution by making it independent from the MAC layer technology used, allowing nodes mobility of in a heterogeneous environment made of IEEE 802 technologies and different technologies for mobile access. The architecture proposed by the standard 802.11 ac can be used as reference to integrate the proposed 
solution the possibility of having mobility across the heterogeneous network ecosystem, thus offering a solution to ensure continuity of service and the quality of experience to higher levels while the details associated with the particular technology and with events and performance metrics associated with the mobility of the nodes are hidden.

\section{Conclusions}

This work shows the results of the FHAMIPv6/MPLS integration and its characteristics to provide QoS. Additionally, it is relevant because it is a pioneer in adapting the FANET capabilities of fast and hierarchical transfer of IP extension to hybrid and FANET environments with MPLS. Here is the basis for future research in real environments.

In this study, it was possible to integrate the FHAMIPv6 and MPLS protocols to provide Quality of Service in flying ad hoc network (FANETs) scenarios through simulation in NS. The requirements were identified and the simulation architecture was defined based on them. Furthermore, delay, fluctuation, performance, TCP congestion window, and packet loss were defined as QoS metrics. These metrics were measured, evaluated, and analyzed in detail.

As an unexpected result, packet delay, performance, and loss metrics were found not to reduce when the number of nodes (drones) is increased. On the other hand, the performance shows a behavior inversely proportional to the number of nodes. However, the performance trend is to stabilize for high node volumes. It can be concluded that the FHAMIPv6/MPLS integration is useful for providing QoS in hybrid scenarios with large numbers of nodes.

The quality of services in flying ad hoc networks is very different in practice compared to drone simulation networks and, in particular, swarms. But the simulation offers a perspective on the behavior of the swarm to provide quality services with 40 or more drones.

\section{Future Work}

It is feasible to deploy swarms with an unlimited number of drones using different technologies, but without taking into account the quality of the service metrics. Flight autonomy greater than or equal to one hour can be provided using a swarm charging station, thus providing better quality of experience for the end customer. There is currently work in progress with the swarm to be able to offer services represented by the addition of: an optical heliport, a control and monitoring system in the field, an artificial intelligence module to optimize the management of the FHAMIPv6 agent, an automatic learning system according to the level of service and the application area and an artificial intelligence module on board. The services will be integrated with the data management platform (ORACLE) for the analysis of large volumes of data, in particular video. Similarly, a list of services is offered that allows the end customer to better analyze their data and, in turn, better business intelligence for decision-making, in order to obtain a greater profit and return on investment.

Funding Statement: This research has been funded by Dirección General de Investigaciones of Universidad Santiago de Cali under Call No. 01-2021.

Conflicts of Interest: The authors declare that they have no conflicts of interest to report regarding the present study. 


\section{References}

[1] S. Patel and H. Pathak, "A mathematical framework for link failure time estimation in MANETs," Engineering Science and Technology, An International Journal, vol. 25, pp. 1-9, 2021.

[2] F. Lee, "Routing in MANET ad hoc networks," in Xin Wang (Ed.), MANET Ad-Hoc Networks: Protocol Design, London, United Kingdom, IntechOpen Limited, pp. 299-322, 2011.

[3] R. Hsieh, A. Seneviratne, H. Soliman and K. El-Malki, "Performance analysis on hierarchical MANET IPv6 with fast-handoff over end-to-end TCP," in IEEE Global Telecommunications Conf., Taipei, Taiwan, China, 3, pp. 2488-2492, 2002.

[4] R. Hsieh and A. Seneviratne, "A comparison of mechanisms for improving MANET IP handoff latency for end-to end TCP," in 9th Annual Int. Conf. on MANET Computing and Networking, MOBICOM 2003, San Diego, California, USA, pp. 29-41, 2003.

[5] J. H. Ortiz, J. Perea and J. López, "Integration of protocols FHAMIPv6/AODV in ad hoc networks," in Network Protocols and Algorithms, $1^{\text {st }}$ ed., vol. 3, Makrothink Institute TM, Las Vegas, Nevada, United States, pp. 82-93, 2011.

[6] J. H. Ortiz, J. Perea, S. Gonzalez and J. López, "AHRA: A routing agent in order to support the hierarchical MANET IPv6 protocol with fast-handover over MANET ad-hoc network scenarios," International Journal of Research and Reviews in Computer Science, vol. 2, pp. 232-237, 2011.

[7] J. H. Ortiz, B. T. Ahmed, D. Santibáñez and A. Ortiz, "Mechanisms to provide quality of service on 4G new generation networks," MANET Networks, vol. 1, pp. 1-32, 2012.

[8] Q. Hu, Q. Huang, B. Han, B. Zhao and J. Su, "MSR: A novel mpls-like secure routing protocol for manet ad hoc networks," in Int. Conf. on Networks Security, Wireless Communications and Trusted Computing, Wuhan, China, pp. 129-132, 2009.

[9] S. Alouneh, A. En-Nouaary and A. Agarwal, "Securing MPLS networks with multi-path routing," in Fourth Int. Conf. on Information Technology (ITNG'07), Las Vegas, Nevada, USA, pp. 809-814, 2007.

[10] S. Sedaghat, F. Adibniya and V. Derhami, "A secure mechanism for QoS routing in MANET ad hoc networks with QoS requirements consideration," in Int. Conf. on Computational Intelligence and Communication Networks (CICN), Bhopal, India, pp. 320-324, 2010.

[11] S. Alouneh and S. Abed, "Fault tolerance and security issues in MPLS networks," in ACS'10: Proc. of the 10th WSEAS Int. Conf. on Applied Computer Science, Iwate, Japan, pp. 167-178, 2010.

[12] L. He and P. Bothan, "Pure MPLS technology," in Third Int. Conf. on Availability, Reliability and Security, Barcelona, Spain, pp. 253-259, 2008.

[13] J. H. Ortiz, J. Perea, J. Ribon and J. López, "Security Issue in FHAMIPv6," in IX Mobile Ad hoc Networks Current Status and Future Trends, CRC Press, Taylor \& Francis Group, London, United Kingdom, pp. 231-250, 2011.

[14] P. Gupta, V. Rishiwal, P. S. Kulkarni and Z. Iqbal, "QoS for video transmission in MANETs: A survey," in 3rd Int. Conf. on Internet of Things: Smart Innovation and Usages, Bhimtal, India, pp. 1-7, 2018.

[15] J. C. Cuellar, J. L. Arciniegas and J. H. Ortiz, "Models to evaluate quality of service in IPtv," 4 Editorial ICESI University, Ediciones especiales, pp. 1-122, 2018. [Online]. Available: https://repository.icesi.edu.co/ biblioteca_digital/bitstream/10906/84047/3/cuellar_modelo_medicion_2018.pdf.

[16] B. Azevedo, C. Couthinho, E. M. Toda, T. Costa and J. Jailton, "Mobile Computing II. Wireless communications challenges to flying ad hoc networks (FANET)," in J. H. Ortiz (Ed.), Mobile Computing, London, United Kingdom, IntechOpen Limited, pp. 1-32, 2020.

[17] C. A. Tavera, J. H. Ortiz, O. I. Khalaf and A. Ríos, "Web application commercial design for financial entities based on business intelligence," Computers, Materials \& Continua, vol. 67, pp. 3177-3188, 2021.

[18] J. Hemanth, C. A. Tavera, J. H. Ortiz, O. I. Khalaf, D. F. Saavedra et al., "Wearable wireless body area networks for medical applications," Computational and Mathematical Methods in Medicine, vol. 2021, pp. $1-16,2021$.

[19] C. A. Tavera, J. H. Ortiz, O. I. Khalaf and W. Montilla, "Software architecture for planning educational scenarios by applying an agile methodology," International Journal of Emerging Technologies in Learning, vol. 16, no. 8, pp. 132-144, 2021. 
[20] C. Narvaez, G. A. Alomia, D. F. Loaiza and C. A. Tavera, "Society 5.0: A Japanese concept for a superintelligent society," Sustainability, vol. 13, pp. 6567, 2021.

[21] N. A. Khan, O. I. Khalaf, C. A. Tavera, M. Sulaiman and M. A. Bakar, "Application of euler neural networks with soft computing paradigm to solve nonlinear problems arising in heat transfer," Entropy, vol. 23, pp. 1053, 2021.

[22] C. A. Tavera, D. F. Castro, J. H. Ortiz, O. I. Khalaf and M. A. Vargas, "Synergy between circular economy and industry 4.0: A literature review," Sustainability, vol. 13, pp. 4331, 2021.

[23] C. A. Tavera, J. H. Ortiz, O. I. Khalaf and A. Ríos, "Business intelligence: Business evolution after industry 4.0," Sustainability, vol. 13, pp. 10026, 2021. 